DEMOGRAPHIC RESEARCH

VOLUME 28, ARTICLE 34, PAGES 981-994

PUBLISHED 15 MAY 2013

http://www.demographic-research.org/Volumes/Vol28/34/

DOI: 10.4054/DemRes.2013.28.34

Research Article

\title{
Societal foundations for explaining low fertility: Gender equity
}

\section{Peter McDonald}

This publication is part of the Special Collection on "Theoretical Foundations of the Analysis of Fertility”, organized by Guest Editors Johannes Huinink, Jens Ehrhardt, and Martin Kohli.

\section{(C) 2013 Peter McDonald.}

This open-access work is published under the terms of the Creative Commons Attribution NonCommercial License 2.0 Germany, which permits use, reproduction \& distribution in any medium for non-commercial purposes, provided the original author(s) and source are given credit. See http:// creativecommons.org/licenses/by-nc/2.0/de/ 


\section{Table of Contents}

1 Introduction 982

$2 \quad$ Gender equity or gender equality? 982

$3 \quad$ Macro- and micro-level influences 985

$4 \quad$ Which contextual differences matter to gender equity and fertility? 986

$5 \quad$ Measurement issues 988

$\begin{array}{lll}6 & \text { Graphical illustrations } & 989\end{array}$

$\begin{array}{lll}7 & \text { Policy considerations } & 991\end{array}$

References 993 


\title{
Societal foundations for explaining low fertility: Gender equity
}

\author{
Peter McDonald ${ }^{1}$
}

\section{Abstract \\ BACKGROUND}

Gender equity theory in relation to fertility argues that very low fertility is the result of incoherence in the levels of gender equity in individually oriented social institutions and family-oriented social institutions. The salience of gender to the fertility transition is strong in theory but not as strong in specification of testable hypotheses, as has been pointed out in the literature.

\section{OBJECTIVE}

The paper aims to clarify the specification of gender equity theory through a discussion of the difference between equity and equality and to suggest methods that might be applied to test the theory.

\section{METHODS}

The theory is restated and further developed using literature from different disciplines. The method is described using a decomposition of fertility for women by human capital levels.

\section{RESULTS}

The clarification of the theory includes a reminder that the theory relates to differences in fertility between countries and not to differences in fertility between women in the same country. In comparisons between countries, higher gender equity leads to higher fertility. In comparisons of fertility across women in the same country, higher gender equity does not necessarily imply higher fertility. In relation to measurement, a specification is suggested that effectively compares women across countries controlling for their level of human capital. Simple graphics are used to indicate ways in which fertility between countries may vary.

\section{CONCLUSIONS}

The paper concludes that it is likely the gender equity theory can be tested more readily by examining the behaviour across countries of women with higher levels of human capital.

\footnotetext{
${ }^{1}$ Australian National University. E-mail: Peter.McDonald@anu.edu.au.
} 


\section{Introduction}

Gender equity theory in relation to fertility argues that very low fertility is the result of incoherence in the levels of gender equity in individually oriented social institutions and family-oriented social institutions. In advanced economies today women are able to compete as equals in the individually oriented institutions of education and market employment. However, they face a dilemma if family-oriented institutions, particularly as reflected in their role within the family, constrain their capacity to fulfil their aspirations as an individual. In this circumstance women must weigh up their aspirations for achievement in market employment against their own and their partner's family aspirations. Some level of compromise between these competing aspirations is inevitable in almost all cases, but where the level of compromise is severe some women will opt to eschew the family role rather than the individual role; that is, they will not form a permanent relationship or they will have no children or fewer children than they had intended. Accordingly, countries that reduce the level of compromise through institutional approaches that support the combination of work and family will have higher fertility than those that leave women with stark choices between work and family (McDonald 2000a, 2000b, 2006).

The above argument about the salience of gender to the fertility transition is strong in theory but not as strong in specification of testable hypotheses, as has been pointed out in the literature (Mills 2010). Nevertheless, the theory still carries weight and it continues to be tested (Balbo et al. 2013) ${ }^{2}$. However, the specification of the theory requires further elaboration.

\section{Gender equity or gender equality?}

In McDonald (2000a), the distinction between gender equity and gender equality was discussed and it was argued that gender equity is the appropriate concept to be applied. Gender equality is a straightforward concept. It can be measured simply by comparing outcomes for men and women in areas such as education, employment, wages, participation, health, and so on. Using the concept of gender equality, the Netherlands is not gender equal in that a high proportion of mothers work part-time while fathers work full-time. For mothers of young children part-time work is quite common in some countries that have relatively high fertility, such as the Netherlands, the United

\footnotetext{
${ }^{2}$ There were full sessions on gender equity and fertility at the 2009 International Population Conference, the 2010 Meeting of the Population Association of America, and the 2010 European Population Conference.
} 
Kingdom, and Australia, while it is uncommon for fathers. Gender inequality defined by equal hours of work does not lead to very low fertility in these instances.

Gender equity is a more subtle and therefore more problematic concept because it allows for different outcomes for men and women, so long as men and women regard the outcomes as fair or at least not grossly unfair and so long as there is equality of opportunity rather than equality of outcome. Thus gender equity is about perceptions of fairness and opportunity rather than strict equality of outcome. In relation to fertility, the equity concept allows for couples to determine the relative caring roles of the father and the mother, so long as both perceive the outcomes to be fair. What each couple considers as being fair will vary from couple to couple and from context to context. Because of this variation the concept of gender equity can be criticised on the grounds that perceptions of fairness are conditioned by the cultural-institutional context, and this is certainly the case. Indeed, this is an essential component of the theory of gender equity and fertility, that fertility decision-making is not mono-cultural and varies across cultures. However, the theory states that low fertility emerges where many (not all) women no longer perceive the prevailing cultural-institutional gender context as being fair. Their partners may be supportive of their decisions. It is the reaction of couples, particularly women, to the institutional context that is important.

According to the theory, perceptions of unfairness arise because individually oriented institutions such as education and market employment open up new opportunities for women. However, if those new opportunities are not supported if they become mothers - by family-oriented institutions - many women will reduce the number of children that they might otherwise have had. Having no or fewer children is a reaction on the part of women to perceived unfairness in the gender system of the cultural context in which they live. It is important to remember that the difference between average fertilities of 1.3 births and 1.7 births is $40 \%$ of women having one fewer child. If some have two fewer children, then reaction against perceived gender inequity needs only to be experienced by around one third of all women to generate very low fertility.

The distinction between gender equity and gender equality is discussed by Nancy Fraser (1994, 2005). In doing this she employs the concept of parity of participation. Fraser states:

The most general meaning of justice is parity of participation. According to this radical-democratic interpretation of the principle of equal moral worth, justice requires social arrangements that permit all to participate as peers in social life. .... People can be prevented from interacting on terms of parity by institutionalised hierarchies of cultural value that deny them requisite standing; in that case, they suffer from status inequality or misrecognition (Fraser 2005: 3) 
In the Netherlands example, if engagement in part-time work when children are young does not involve the perception of a loss of the capacity to participate as a peer in social life or to social inequality or misrecognition, part-time work for mothers can be considered as being gender equitable while not being gender equal. Most Dutch women apparently do not react against the likelihood that they will work part-time if they become mothers. Lewis et al. (2008: 265) argue that the Dutch Government's successful expansion of part-time work opportunities for mothers in the 1990s and early 2000s 'appeared to fit well alongside longstanding labor market behavior and attitudes of Dutch women'. It is evident in the Netherlands and Australia that there is a strong preference for part-time work among mothers of young children, but the institution of work has adjusted in these countries so that mothers can work part-time in their own jobs while still pursuing career progression and obtaining pro-rata employment benefits. It is conventional for employers in these countries to recognise and adjust their workforce planning to the fact that mothers may be working part-time for a period of time and are likely to want to increase their hours as their children get older. Furthermore, minimum wages are high in both countries, meaning that, together with social transfers, most couples can afford to live on less than two full-time incomes for a time. Thus individual- and family-oriented institutions remain compatible and supportive of the preferences of women.

In other contexts part-time work may not be available and full-time work for mothers may not be supported by family-oriented social policy or, alternatively, parttime work may be second-rate work with low wages and little opportunity for career progression. Also, where social benefits are contingent upon full-time employment (as in conventional social insurance regimes), part-time employment may be an inequitable outcome. In these contexts supported full-time work is more likely to provide equitable outcomes. This tends to be the situation in France and the Nordic countries, although the hours actually worked in full-time work in these countries are comparatively low (Lewis et al. 2008).

However in other contexts, where equitable outcomes are contingent upon fulltime work, particularly the Southern European countries and the advanced East Asian countries, support for the combination of work and family is poorly developed and, as a consequence, these countries have very low fertility rates (fewer than 1.5 births per woman). The theory would be confirmed if a large proportion of women in these countries indicated that the gender system was unfair to them by not allowing them to combine work and family in ways that maintained their parity of participation. The challenge for research is to turn this latter statement into questions that are understandable by survey respondents across cultures. Alternatively the issue could be pursued using intensive case studies or focus groups. Questions related to the measurement of perceptions of fairness are not straightforward and language may make 
it difficult for them to be applied consistently across contexts. If asked after the event post-hoc rationalisation may also be a problem, but there is a sense that questions after the fact are more likely to be reliable than questions about the imagined future, as seen in uncritical analyses of fertility intentions. In East Asia research suggests that gender inequity is often reflected in non-marriage because, in those countries, marriage and the first birth are jointly determined; that is, effectively, the decision to marry is equivalent to the decision to have a first birth (Shirahase 2000, McDonald 2009).

Alternatively, it may be possible for researchers in the policy context to evaluate the gender equity level of social institutions within a given context, or a group of researchers could argue the case. For example, there are measures such as the hourly gender wage gap, access to child care for those that need it, the fairness of hours applied to household work by the husband and the wife, and the opportunity cost of having children that can be evaluated from the perspective of fairness. However, the views of researchers about what is fair may differ from the views of those making the decisions about restricting fertility. This is an area in which there is a diversity of views about what is appropriate and, as described above, only $30 \%$ of women in a particular context need to consider the arrangements as unfair to produce very low fertility. If researchers' views are more in keeping with the other $70 \%$, then the researchers' views of fairness will not be a reliable measure of the impact of perceived gender inequity on fertility. Nevertheless, because social policy is often based upon evaluations and ideas of experts followed by public discussion of their views, this social evaluation approach is very likely to occur.

\section{Macro- and micro-level influences}

The purpose of gender equity theory is to provide an explanation for observed differences in fertility across countries or, less specifically, across varying institutional contexts. While the theory has often been applied to investigate fertility across individuals within a single context, this is not its purpose. This is not to say that individual analysis within a single context is not useful to investigation of the theory. Decision making about fertility is made at the individual level and it is incumbent upon any macro theory to demonstrate how the theory is played out at the micro level. However, with its emphasis on the nature of institutions, the theory can only be tested across contexts using contextual level variables.

In simple terms, fertility will be lower in Country A than in Country B if a higher

proportion of women in Country A, either alone or jointly with their partner, decide not to have a child or an additional child because of the adverse effect that the additional 
child will have upon their lives. There are three main circumstances in which this may apply:

1. The direct financial costs of the child are considered to be too high.

2. The indirect financial costs (opportunity costs) through lost earnings of the mother are considered to be too high.

3. It is perceived that the additional child will prevent the mother realising her desired human capital aspirations leading to 'status inequality or misrecognition’.

The first circumstance, the direct costs argument, is likely not to be a matter of gender equity and is more likely to be a decision of the couple. Direct cost is more about the perceived or actual financial circumstances of the couple and might, for example, be driven by uncertainty about the future income of the potential mother's partner rather than by her circumstances. The direct cost argument is likely to become more salient as the number of the couple's children rises (Carmichael 2013). At lower parities it is possible that the perceived direct costs of the next child may affect the timing of the next birth.

The second and third circumstances listed above both relate to gender inequity that women lose income or status when they become mothers, while men who become fathers do not.

\section{Which contextual differences matter to gender equity and fertility?}

Women's education levels and their capacity to compete with young men in the employment market have advanced rapidly since the 1970s in all developed countries. While they remain childless, young women today are on an almost equal plane with men in relation to education and employment. Indeed, in most advanced countries today, young women are more highly educated than young men. Almost inevitably, in all societies, having a baby will change this circumstance and make it more difficult for young women to compete with young men and non-mothers in the employment market. The impact of pregnancy, childbirth, breastfeeding, and the nurturing role of the mother upon her capacity to compete in market employment will rarely be trivial. The issue for gender equity theory is whether the individual woman considers this impact to be unfair in the given institutional context. Gender equity theory argues that more women will consider the impact to be unfair in countries where social institutions do not provide strong support to the combination of work and family, including the capacity to spend 
time out of the labour force when children are very young. Gender inequity is more likely in cultures where men and women are considered to be complementary to each other (complementarianism), having different and specialised roles.

As complementarianism (the breadwinner model) reached its zenith in the 1950s, the seeds of its failure were already being sown through increasing levels of education for both women and men. The 1960s brought on second-wave feminism, later marriage, the employment of women before marriage in career-oriented jobs, modern contraception, cohabitation, easier abortion, no fault divorce, and, symbolic of all of these changes, the capacity for individuals to pursue their own goals less constrained by socially-defined roles (McDonald 1988). These changes brought about profound changes in the lives of young women, leading to the situation already described: that, in most advanced social contexts, young women are able to compete with young men in the employment market - so long as they do not have children.

From the 1970s onwards, the Nordic countries, the French and Dutch-speaking countries, and the English-speaking countries moved at varying speeds towards different models that supported the combination of work and family. Social democratic countries did this mainly through the provision of state services funded by the tax system. Liberal economies achieved the same aims through more market-oriented approaches, including lower taxation, subsidised childcare, and income transfers through the tax transfer system (McDonald and Moyle 2010). Importantly, women as activists were often involved in political action in these countries to achieve the ends that they required. Partly because of this each country has a different 'package' of supportive policies, but the package that each has achieved is appropriate to the values and needs of most women in the country. While the revolution is as yet incomplete (Esping-Andersen, 2009), what has been achieved generally is in keeping with the directions that most women in the particular social (and welfare) context consider fair. The proportions reacting against the social-institutional regime are therefore relatively small.

In contrast, reform has been much more difficult to achieve for women in the countries where complementarianism has remained strong, such as in the Southern European countries and the German-speaking countries. This is also the case for women in the East Asian liberal economies, but, in addition to complementarianism, in East Asia the opposition of employers to reduction of work hours and other family-friendly employment policies has prevented reform. In these countries the proportions of women who react against the regime are sufficient to produce very low fertility. Indeed, increasingly in these societies, women appear to be expressing a strong reaction against the institutional regime by not marrying or not having children at all. 


\section{Measurement issues}

It is a reasonable assumption that women who react against the social-institutional context of childbearing are selective of those that have more to lose. Loss of income or status will increase as the woman's human capital level increases and reaction will be more common at higher levels of human capital. Thus, gender equity theory can be investigated by examining fertility outcomes and determinants for women by human capital level and across social contexts. To back up this approach it would be useful to examine whether perceptions of fairness of the gender system are also associated with human capital. This would help to link the empirical results from the proposed models to the theory.

To investigate the role of the woman's human capital, we need to consider a decomposition of societal level fertility into the fertility of women with differing levels of human capital. Consider a cohort of women in a given society. Using a discrete representation, their average completed fertility, f, can be expressed as:

$$
f=\sum_{i} \sum_{j} j \cdot f_{i}(j) \cdot h(i)
$$

where: $j=$ completed parity, $f_{i}(j)=$ the frequency distribution across the range of completed parities $j$, for women in human capital category $i, h(i)=$ the frequency distribution of women across the range of human capital categories.

More simply, we can write:

$$
f=\sum_{i} f(i) \cdot h(i)
$$

where: $f(i)=$ the average completed fertility for women in human capital group $i$.

Finally, average completed fertility for women in human capital group $i$ can be written as a product of the parity progression rates of the cohort:

$$
f(i)=p\left(p_{0 i}, p_{1 i}, p_{2 i}, p_{3 i}, p_{4 i}, \ldots\right)
$$

where: $p_{j i}=$ the parity progression rate from parity $j$ to parity $j+1$ for women in human capital group $i$.

With these formulations it is possible to compare differences in fertility across societies or changes in fertility across time in one society in terms of movements in the distribution functions shown in the equation. The same expressions can be considered cross-sectionally using the Total Fertility Rate and period parity-specific progression 
ratios for each human capital group. Differences in cross-sectional fertility across two or more contexts can be decomposed into the period parity progression rates of comparative human capital groups, or even combinations of parity progression (e.g., progression from zero births to two births). The determinants of the main observed differences can then be investigated using multi-level models. Note, period parity progression ratios will be affected by changes in the timing of births (tempo) and this may have to be considered in the interpretation.

\section{Graphical illustrations}

The following graphs depict three varying comparisons between a very low fertility country (Country A) and a moderately low fertility country (Country B) using average completed fertility (or TFR) for three human capital groups. In the first instance, fertility is higher (by the same amount) for each human capital group in Country B than in Country A. This may be more the case where Country B is an English-speaking country. In the second illustration, higher fertility in Country B derives from much higher fertility for high human capital women. Maybe this is the case for France. Finally, in the third illustration, higher fertility is achieved through women of different human capital levels having the same number of children. This may be more the case in the Nordic countries. In all three examples fertility is higher in Country B than in Country A for women with the highest level of human capital. This is not necessarily the case for women with lower levels of human capital. Thus, the gender equity hypothesis is more likely to be proven by examining the comparative fertility levels of women at higher levels of human capital. 
Figure 1: Completed fertility, human capital groups

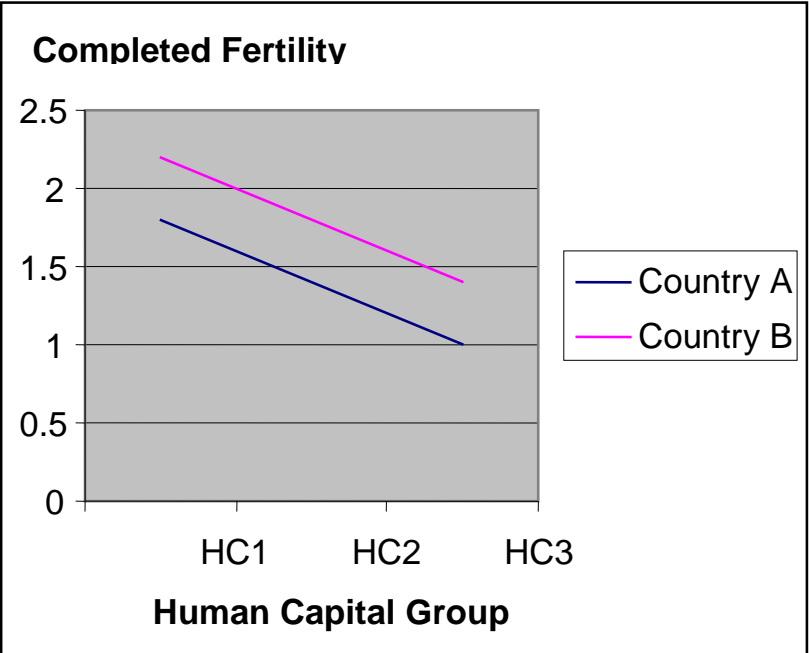

Figure 2: Completed fertility, human capital groups

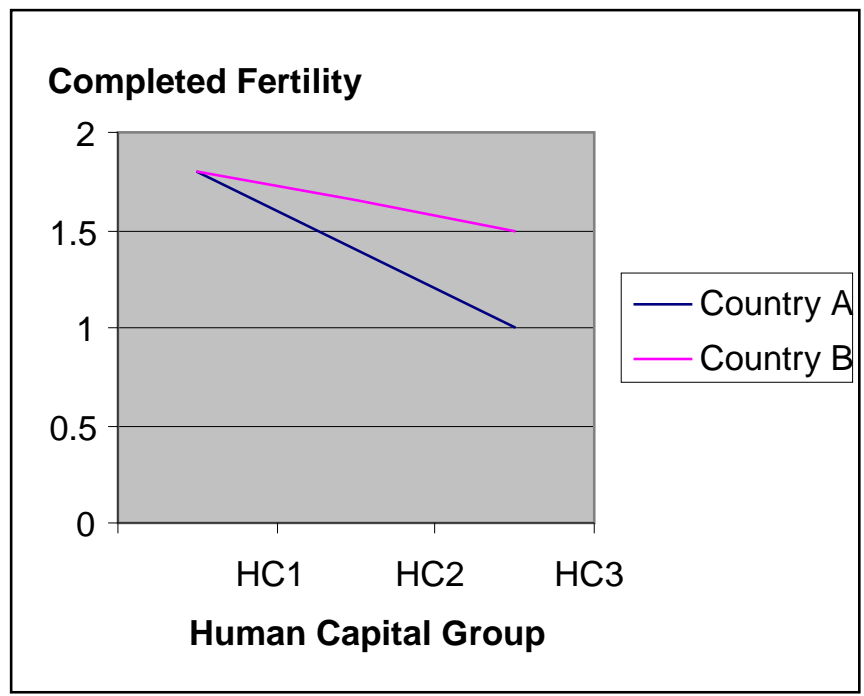


Figure 3: Completed fertility, human capital groups

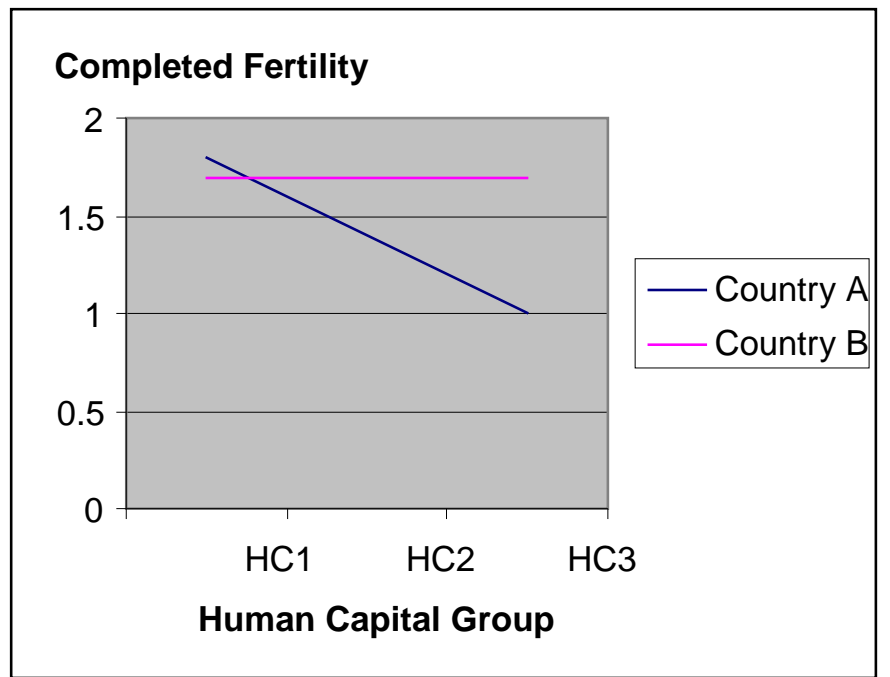

\section{Policy considerations}

Fertility in advanced countries over decades has been divided into those with a Total Fertility Rate above 1.5 births per woman and those with a TFR below 1.5 (very low fertility). This divide has become a major policy issue in Europe and why it occurs has been the subject of numerous European studies.

The strongest conclusion from European research is that fertility falls to very low levels when women must make stark choices between work and family, choices that do not apply to men. Fertility is argued to be relatively high in countries such as France and the Nordic countries because these countries have family policy regimes in place that support the combination of work and family. In contrast, family support policy is weak in the countries with very low fertility. 
From the European research, the family policies that are said also to support fertility are:

- state-subsidised childcare and early childhood education

- income transfers through the tax or transfer systems that support families with children

- work place policies such as paid parental leave, family carers' leave, and flexible working hours.

The argument that state support for the combination of work and family is the key to sustainable levels of fertility was made in the 2005 European Commission Green Paper on demographic change (European Commission 2005). It has also been used to support work/family policy initiatives in various European countries, especially in Germany from 2007 (Lewis et al. 2008). It is a sensible approach for governments to increase or sustain fertility through support of the combination of work and family for mothers. If they are working they will pay taxes that can be used to pay for the services that they require. Furthermore, Luci and Thevenon (2010) have shown that the association between higher fertility and higher GDP per capita, as shown by Myrskylä et al. (2009), is not so much the result of wealth alone but of the higher labour force participation rates for women in the highest income countries. In turn, these are countries that have focused on policies that support the combination of work and family. This argument is supported by outcomes in the Nordic countries and in the English-speaking countries. 


\section{References}

Balbo, N., Billari, F., and Mills, M. (2013). Fertility in advanced societies: A review of research. European Journal of Population 29(1): 1-38. doi:10.1007/s10680-0129277-y.

Carmichael, G. (2013). Decisions to Have Children in Late $20^{\text {th }}$ and Early $21^{\text {st }}$ Century Australia: A Qualitative Analysis. Dordrecht: Springer. doi:10.1007/978-94-0076079-0.

Esping-Andersen, G. (2009). The Incomplete Revolution: Adapting to Women's New Roles. Cambridge: Polity Press.

European Commission (2005). Confronting demographic change, a new solidarity between the generations. Brussels: European Commission.

Fraser, N. (1994). After the family wage: Gender equity and the welfare state. Political Theory 22(4): 591-618. doi:10.1177/0090591794022004003.

Fraser, N. (2005). Reframing justice in a globalising world. New Left Review 36 (November-December).

Lewis, J., Knijn, T., Martin, C., and Ostner, I. (2008). Patterns of development in work/family reconciliation policies for parents in France, Germany, the Netherlands and the UK in the 2000s. Social Politics 15(3): 261-286. doi:10.1093/sp/jxn016.

Luci, A. and Thevenon, O. (2010). Does economic development drive the fertility rebound in OECD countries? Paris: INED - Institut National d'Etudes Démographiques.

McDonald, P. (1988). Families in the future: The pursuit of personal autonomy. Family Matters 22: 40-47.

McDonald, P. (2000a). Gender equity, social institutions and the future of fertility. The Journal of Population Research 17(1): 1-16. doi:10.1007/BF03029445.

McDonald, P. (2000b). Gender equity in theories of low fertility. Population and Development Review 26(3): 427-439. doi:10.1111/j.1728-4457.2000.00427.x.

McDonald, P. (2006). Low fertility and the state: The efficacy of policy. Population and Development Review 32(3): 485-510. doi:10.1111/j.1728-4457.2006.0 0134.x. 
McDonald, P. (2009). Explanations of low fertility in East Asia. In: Jones, G., Straughan, P., and Chan, A. (eds.). Ultra-low Fertility in Pacific Asia: Trends, Causes and Policy Issues. Oxford: Routledge.

McDonald, P. and Moyle, H. (2010). Why English-speaking countries have relatively high fertility? Journal of Population Research 27(4): 247-273. doi:10.1007/ s12546-010-9043-0.

Mills, M. (2010). Gender roles, gender (in)equality and fertility: An empirical test of five gender equity indices. Canadian Studies in Population 37(3-4): 445-474.

Myrskylä, M., Kohler, H.-P., and Billari, F. (2009). Advances in development reverse fertility declines. Nature 460: 741-743. doi:10.1038/nature08230.

Shirahase, S. (2000). Women's increased higher education and the declining fertility rate in Japan. Review of Population and Social Policy 9: 47-63. 